\section{Evaluation of a course on the operation and management of a local decontamination unit for undergraduate dental students}

\author{
D. E. A. Lockhart, ${ }^{1}$ K. Chapman, ${ }^{2}$ D. J. Hurrell ${ }^{3}$ and A. J. Smith ${ }^{4}$
}

IN BRIEF

- Provides a model of dental undergraduate education in decontamination sciences.

- Provides a series of learning outcomes in decontamination sciences for dental education.

- Describes a new e-learning programme for decontamination sciences.

- Describes student evaluation of new model for teaching decontamination sciences.

\begin{abstract}
Objective Describe the formulation of learning outcomes and evaluate a new course for undergraduate dental students in managing a local decontamination unit (LDU). Design, sample and setting This was a retrospective analysis of questionnaire data from the first cohort of dental students completing the LDU managers course in a UK dental school. Methods All final year dental students were invited to complete a course evaluation. Data were collated via an anonymous semi-structured questionnaire distributed at a post-course session. Results A response rate of 95\% was achieved. The majority (89\%) improved their knowledge of decontamination and felt that the course material was relevant (81\%) to their future role as a dental practitioner. Students stated that the practical elements of the course provided a valuable educational experience, while tutorials on health and safety and quality management systems proved less popular. The use of an e-learning programme to support the lectures and practical sessions was also useful in achieving the learning outcomes. The one-week intensive course proved challenging for both students and staff. We identified short comings both locally and nationally in the availability of appropriately trained staff to teach this core topic. Conclusion We describe a series of learning outcomes to support competencies in instrument decontamination for dental undergraduates and a purpose built training facility. The evaluation of the course suggests this model meets current and future General Dental Council (GDC) requirements for training of dental undergraduates. We identified a shortage of appropriately qualified teachers in this subject area and recommend that these deficiencies are addressed as part of a coordinated national strategy.
\end{abstract}

\section{INTRODUCTION}

A number of surveys have highlighted deficiencies in the reprocessing of medical devices in facilities ranging from Sterile Service Departments, ${ }^{1}$ endoscopy reprocessing units ${ }^{2}$ to general dental practice. ${ }^{3,4}$ A key finding of these surveys has been the observation that the training and education of staff involved in the decontamination process was poor. Despite these shortcomings, staff were frequently observed to be highly

\footnotetext{
Specialist Registrar/Honorary Clinical Teacher Microbiology, University of Glasgow Dental Hospital \& School Faculty of Medicine, 378 Sauchiehall Street, Glasgow G2 3JZ; ${ }^{2}$ Senior Nurse, Clinical Practice, NHS Greater Glasgow \& Clyde, Central Decontamination Unit, Cowlairs Industrial Estate, 24 Finlas Street, Glasgow, G22 5DT; ${ }^{3}$ Authorising Engineer (Decontamination), Healthcare Science Limited, Bury Mead Road, Hitchin, Hertfordshire, SG5 1RT: **Senior Clinical Lecturer/Honorary Consultant Microbiologist, University of Glasgow Dental Hospital \& School, Faculty of Medicine, 378

Sauchiehall Street, Glasgow G2 3JZ

Correspondence to: Dr A. J. Smith

Email:a.smith@dental.gla.ac.uk
}

\section{Refereed Paper}

Accepted 2 July 2009

DOI: $10.1038 /$ sj.bdj.2009.820

${ }^{\circledR}$ British Dental Journal 2009; 207: 285-289 motivated and attempting, often unsuccessfully, to comply with infection control and instrument decontamination guidelines.

In general dental practice a large scale observational study reported that staff training in decontamination was provided mainly by demonstration and observed practice, and that less than 10\% of surgeries had any documentation associated with training. ${ }^{3-5}$ In particular there were no records of staff training in the use of sterilisers in 90\% of surgeries. ${ }^{5}$

The General Dental Council's The first five years $(2008)^{6}$ stipulates that the BDS curriculum should provide 'the knowledge, skills and attitudes ... to join our registers' and in terms of instrument decontamination, 'have knowledge of the scientific principles of sterilisation, disinfection and antisepsis'. These requirements highlight the dilemma of ensuring competency in producing sterile dental instruments in a dental practice setting within a very broad learning outcome.

Following publication of the survey of decontamination in general dental practice ${ }^{7}$ a review of the teaching of instrument decontamination in the undergraduate teaching programme was undertaken at the University of Glasgow Dental School. A number of deficiencies in the programme were noted including the absence of practical training in the cleaning, sterilisation, storage, record keeping and management of instrument decontamination. The poor levels of practical training were reflected by an absence of adequate facilities to teach instrument decontamination in a safe, controlled and regulatory compliant decontamination facility.

As a result of these findings there was a clear need for a more appropriate teaching programme in this topic. A new programme of teaching was devised in conjunction with the construction of a purpose built Local Decontamination Training Unit. Our model for educating and training undergraduate dental students is divided into core infection prevention skills developed under the title of Cleanliness Champions $^{9}$ and Decontamination 
Sciences. The Cleanliness Champions programme runs from year 1 to year 3 with the Decontamination Sciences course following on from year 3 to year 5 .

The aim of this paper is to describe the learning outcomes and logistics of setting up a new course in dental instrument decontamination and evaluate the views of the first cohort of undergraduate dental students to complete the programme.

\section{MATERIALS AND METHODS}

\section{How the learning outcomes were determined}

The establishment of learning outcomes were developed by constructing a process map of the LDU processes (ranging, for example, from set down of contaminated instruments, manual washing, ultrasonic cleaning, automated cleaning, drying, inspection, sterilisation and storage). For each process stage we identified relevant activities and responsibilities for staff members from which we could identify the relevant knowledge and skills required. This led to the identification of learning outcomes

\section{Review of standards, guidelines and courses for learning outcomes}

In addition to the process mapping exercise a review of the technical memorandum $2010,{ }^{10,11} 2030^{12,13}$ and the Health Protection Scotland local decontamination unit guidelines $^{8}$ provided a useful framework for the development of the training programme. A number of technical guidelines, ${ }^{8,10-14}$ specialist societies, ${ }^{15}$ training organisations, ${ }^{16}$ Scottish/ National Vocational Qualifications (S/NVQ) in decontamination ${ }^{17}$ and regulatory body ${ }^{6}$ literature were also consulted to determine if learning outcomes and competencies were available that may be incorporated into the training of dental undergraduates.

\section{How the courses were constructed}

The Decontamination Sciences course is structured to deliver a basic level of knowledge and competency articulated towards the 'operator' level ${ }^{9}$ or $\mathrm{S} / \mathrm{NVQ}^{17}$ level 3 in year 3 (Table 1). This is built upon in Year 4 and delivered to 'user' ${ }^{9}$ level (Table 2). These courses feature a combination of lectures and practical classes. Assessment comprises written assignments and a number of written questions in the Clinical Medical Sciences examination.

\section{Table 1 Leaning outcomes for 'operator' level}

\section{Operator level - Year 3}

Description: The person with authority to operate decontamination equipment, including noting instrument readings and simple housekeeping duties.

On completion of the course an operator should:

Define their role and responsibilities as an operator

Awareness of the decontamination cycle

Awareness of legislation, standards and guidelines

State the purpose (role) of cleaning, disinfection and sterilisation

Be able to collect used equipment from clinical areas

Be able to sort used equipment and dispose of waste from returned items

Be able to read and understand manufacturers instructions on decontamination

Prepare re-usable medical devices for cleaning (explain reasons for correct usage and loading of ultrasonic cleaners and automated washer disinfector)

Prepare re-usable medical devices for sterilisation (explain reasons for correct usage and loading of steriliser)

Prepare load and operate decontamination equipment (carry out periodic daily testing on equipment)

Monitor procedures (daily test level)-completion of records (complete test records accurately and precisely)

Perform house keeping duties on equipment

\section{Table 2 Learning outcomes for 'user' level}

User level - Year 4

Description: The person responsible for the day to day management of the decontamination equipment. On completion of the course a user should:

Have a thorough working knowledge of decontamination processes

State the main responsibilities of key personnel defined in HTM 2010/30

Certify that the decontamination equipment is fit for use

Identify appropriate documentation for decontamination equipment and process records

Define steam sterilisation and various cleaning processes

Describe the operating principles of a washer disinfector and ultrasonic

Describe the operating principles of a Type B, N \& S benchtop steam steriliser

State the periodic tests required for decontamination equipment

Interpret test results provided by the Test person to enable decisions to be reached on whether or not equipment is fit and safe to be used

Describe record keeping procedures

Awareness of training records

Maintain production records to establish procedures for product release

In year 5 (final year) the students undertake a LDU managers course (Table 3). This comprises a series of lectures and practicals in the use of manual washing, ultrasonic cleaning, automated washer disinfectors and benchtop steam sterilisers both individually and as part of a full decontamination process. There are also tutorials in health and safety and the application of quality management systems in dental practice. In addition the students complete an e-learning programme on instrument decontamination specifically written for LDUs. ${ }^{18}$ Finally, students are required to pass a written examination and complete a 2,500 word essay on a choice of decontamination science topics.

\section{How the course was delivered}

\section{Facilities and equipment}

In order to deliver effective teaching and training in instrument decontamination the main focus would be on developing 


\section{Table 3 Learning outcomes for 'manager' level}

Manager level - Year 5

Description: The person ultimately accountable for the operation of a LDU.

On completion of the course a manager should:

Describe the decontamination cycle

State the main responsibilities of key personnel defined in HTM 2010/2030

Have knowledge of the training required for operator and user levels

Identify appropriate documentation

Define the procurement process for acquisition of equipment and instruments

Define various cleaning processes

Define the steam sterilisation processes

Describe the operating principles of manual washing and ultrasonic cleaners

Describe the operating principles of automated washer disinfectors

Describe the operating principles of a type N, B and S benchtop sterilizer

State the periodic tests required

Interpret test reports provided by the test person

Describe the management requirements for an LDU

Describe the principles of a Quality Management system

Describe the requirements for the layout of an LDU

Be familiar with LDU guidance documents

practical skills. This required the availability of purpose built teaching facilities distinct from operational decontamination units. These were either already fully committed to providing a clinical service or unsuitable for undergraduate training (for example, Sterile Service Departments). Requirements for a Local Decontamination Training Unit (LDTU) included compliant decontamination equipment that had been validated and periodically tested as per regulatory standards; a processing environment that segregated processed instruments from unprocessed instruments and appropriate environmental controls. ${ }^{8}$ In addition the unit should have audio-visual facilities and have sufficient capacity for delivering practical training. The LDTU was commissioned and constructed to allow maximal usage of a relatively small area using a novel design that consisted of mobile $600 \mathrm{~mm}$ x $600 \mathrm{~mm}$ stainless steel cabinetry with services (such as electricity, hot, cold and reverse osmosis water, drains) supplied behind a service gantry (Figs 1-2). The mobile design allows the training facility set up to be modified for different types of practical exercises.

\section{Timetabling}

The major timetabling challenges were the requirements for small group teaching (6-8 students) within the LDTU as clinical commitments in outreach practices constrained access times for the students. To address this, the year were divided into two groups ( $n=45$ in each group) and a one-week intensive course timetabled for each group. The timetable was designed around a rotation of different activities for five groups of eight students, culminating in an examination at the end of the course. The different activities comprised lectures, practical sessions, tutorials, e-learning and study time.

\section{Personnel}

Due to the timetabling of the course and necessity for small group teaching for a relatively large cohort of dental students, a number of personnel trained in decontamination sciences were required. Recruitment of staff with relevant experience proved difficult. For the programme to run effectively we recruited nine members of staff for the two week teaching programme. The staff recruited to teach in the programme included an authorising engineer, test

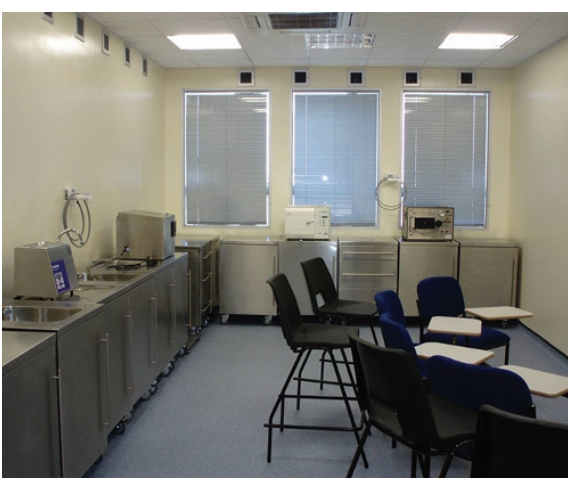

Fig. 1 Photograph of Local Decontamination Training Unit: demonstrating mobile modular stainless steel work units

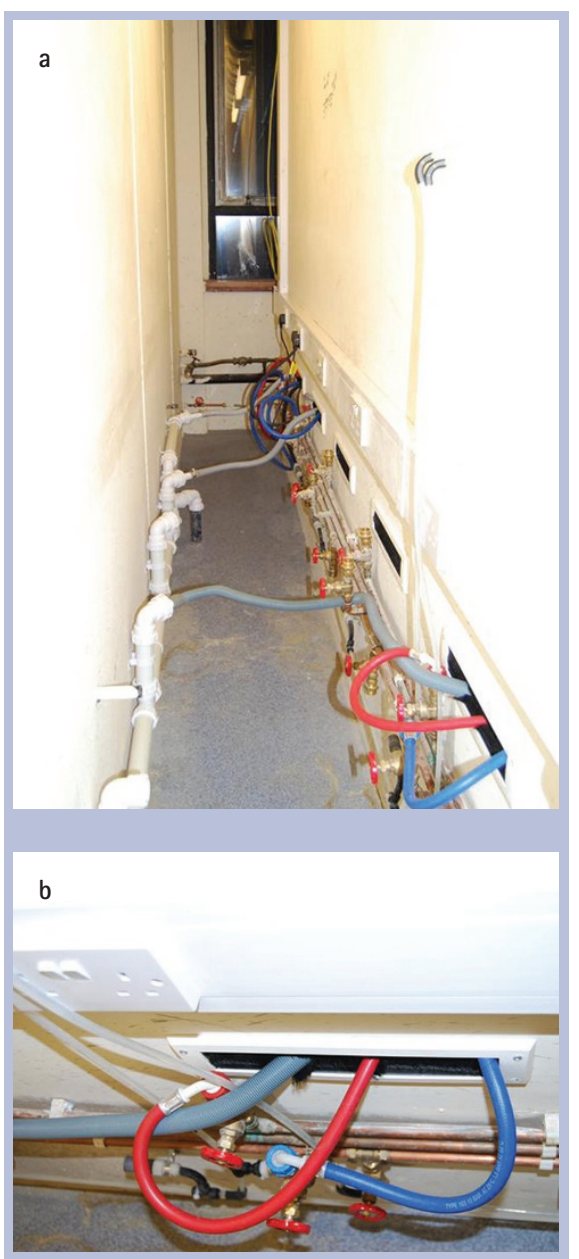

Fig. 2 Photograph of service access for local decontamination unit: demonstrating supply of hot, cold water, reverse osmosis water, drains and electricity supply. 2a Service gantry, $2 b$ Supply of hot/cold tap water, $\mathrm{RO}$ and drainage through 'service docking station'

engineer, a senior nurse and two dental nurses (trained in local decontamination policies and procedures), Consultant Microbiologist, Specialist Registrar in Microbiology, dental defence society practitioner and a dental practice advisor. 


\section{Local decontamination} e-learning programme

NHS Education for Scotland (NES) recently released an e-learning programme comprising nine modules (Table 4). Each module has learning outcomes and may require completion of a work place activity, online quiz and a reflective account of the learning. The students were allocated study time and several subsequent weeks to complete the programme and submit their learning portfolio.

\section{Evaluation}

All final year students attending a postcourse session were invited to submit an anonymous semi-structured questionnaire relating to their views on the application of decontamination sciences in clinical practice and the LDU managers course itself. The questionnaire comprised a range of closed and open questions. Only one answer was permitted in the closed questions, however, open questions allowed elaboration of these areas in an unrestricted format.

\section{RESULTS}

Questionnaires were returned by 76/80 students giving a response rate of 95\%. Each of the closed questions were answered by 95-100\% of the students. Encouragingly, 89\% stated their knowledge of decontamination had improved and $81 \%$ found the course relevant to their future role as a general dental practitioner. Overall, 88\% of students felt the course was well organised and 73\% believed that the course was presented in a way that helped them achieve the learning outcomes. Although 76\% of students felt that the lectures provided a good theoretical background to the course, the practical classes provided a more valuable experience.

Responses to the open questions revealed that the students had a positive experience from the 'hands-on' elements of the course with a relevant content to their future role as a general dental practitioner. Many felt that they had benefited from a more indepth knowledge of the validation, testing and operation of the equipment used in the course. There was an overwhelming response for more detailed education and training on the economic and business management aspects of dental practice which was touched upon in the

\begin{tabular}{|c|c|}
\hline Module & Objectives of module \\
\hline Decontamination - An overview & $\begin{array}{l}\text { Explain how contamination can cause infection } \\
\text { Describe the stages of the decontamination cycle } \\
\text { List the key requirements of your role }\end{array}$ \\
\hline Microbiology & $\begin{array}{l}\text { Identify the different types of microbes, outline the history of germ } \\
\text { theory, identify the constituent elements of microbes, identify the } \\
\text { different methods used to inactivate microbes, state what is meant } \\
\text { by sterile. }\end{array}$ \\
\hline Acquiring medical devices & $\begin{array}{l}\text { Describe best practices for purchasing medical devices, describe best } \\
\text { practices for borrowing and lending medical devices, explain the } \\
\text { meaning of manufacturers symbols on medical devices }\end{array}$ \\
\hline Protecting yourself and others & $\begin{array}{l}\text { Recognise health and safety hazards, describe and manage the risk of } \\
\text { personal injury and infection, describe and manage environmental risks. }\end{array}$ \\
\hline Cleaning and disinfection & $\begin{array}{l}\text { Explain the cleaning processes for medical devices, outline the } \\
\text { differences between washer/disinfectors and ultrasonic cleaners, } \\
\text { describe the different cleaning methods available and give a } \\
\text { rationale for using each one, identify the preferred method of } \\
\text { cleaning, describe disinfection methods, identify differences between } \\
\text { disinfection and sterilisation, describe chemical disinfection. }\end{array}$ \\
\hline Inspection \&t packaging & $\begin{array}{l}\text { Identify characteristics of the inspection zone, explain the different } \\
\text { inspection techniques, undertake inspection and take appropriate action } \\
\text { on all non-conforming medical devices, explain the role of packaging } \\
\text { in the decontamination process, list the characteristics of the } \\
\text { materials used in packaging, explain when packaging is appropriate } \\
\text { before sterilisation, explain the purpose of a process indicator } \\
\text { (chemical), recite the information required on a label to allow tracking. }\end{array}$ \\
\hline Sterilisation & $\begin{array}{l}\text { Explain the principles of sterilisation, describe the different types } \\
\text { of steam steriliser cycles, how they work and their correct use, } \\
\text { describe the essential tasks undertaken by the operator and the } \\
\text { documentation required as evidence of successful sterilisation. }\end{array}$ \\
\hline $\begin{array}{l}\text { Waste management, transportation } \\
\text { of medical devices \& storage }\end{array}$ & $\begin{array}{l}\text { Identify the requirements for safe waste management, identify the } \\
\text { requirements for safe transportation of medical devices, identify the } \\
\text { requirements for safe storage }\end{array}$ \\
\hline Ensuring quality & $\begin{array}{l}\text { Identify the requirements of a decontamination management system, } \\
\text { define benefits of a decontamination management system, highlight } \\
\text { the documentation required in a decontamination management } \\
\text { system, stipulate the current guidance and documents which guide a } \\
\text { decontamination management system, specify the requirement for a } \\
\text { traceability system }\end{array}$ \\
\hline
\end{tabular}

tutorial on quality management systems. Nevertheless, the one-week intensive course together with project work, examination and e-learning modules after the summer vacation proved challenging for many of the students.

\section{DISCUSSION}

Before the introduction of the Decontamination Sciences course the training of this core topic in Glasgow lacked important features such as practical experience of cleaning and sterilising dental instruments, awareness of equipment testing protocols, record keeping and management skills. The findings of the national survey of instrument decontamination in dental practice supports the view that training and education in this field has been sub-optimal. Devising the course described in this paper attempts to address these deficiencies and demonstrates a model for the delivery of a defined set of learning outcomes. These were derived from a process mapping exercise and a number of national guidelines and standards that could form the basis for a nationally agreed training programme in this subject area.

Having determined the learning outcomes for this core subject area there were several challenges involved in setting up the course. The requirement to accommodate teaching small group practical sessions from a large cohort of undergraduates with limited facilities and equipment requires careful planning with adequate financing of capital and revenue costs. All equipment must undergo regular periodic testing and 
maintenance as per national standards. Records from this type of activity help develop teaching aids and awareness for the students. Perhaps the greatest challenge in setting up courses in this subject area is a national shortage of trained and competent personnel to prepare, deliver and assess the training material. We felt it was vital that trainers had undergone some form of recognised training in the decontamination of surgical instruments and that clinical qualifications (dentistry, nursing) were inadequate.

The course offered a variety of learning methods ranging from lectures, practicals, tutorials, e-learning and self directed project work. Although the feedback from the first cohort to undertake the course was positive, we acknowledge that this method of delivery was intensive for both staff and students. The scheduling of the programme was, however, constrained by timetabling restrictions with other elements of the final year curriculum.

At this stage of development of the LDU manager's course the students' competencies were assessed by a written examination featuring a combination of multiple short answers, single best answer and the submission of project material. These methods of assessment are arguably insufficient to evaluate practical skills in this topic and although logistically demanding, work is ongoing to develop practical tests to determine competencies in this field. At present a practical assessment is incorporated into a station in the year 5 observed structured clinical examination (OSCE).

In conclusion, we describe a two component infection prevention and instrument decontamination training programme for undergraduate dental students that appear well received by the students. Both programmes address core elements of the recommendations made by the GDC applicable to undergraduate education. We have used a number of different learning methods in the programme with an emphasis on practical skills for instrument decontamination. Further work is ongoing to improve the assessment of competencies in this area. Of concern is the shortage of appropriately qualified trainers in the field of decontamination sciences and we recommend a national scheme to establish the necessary experience, competencies and qualifications required to teach this core subject area.

The authors wish to thank Lee MacArthur, Lynda Clark, Irene Black (NES Decontamination advisors), Andrew Hadden (MDDUS) and Malcolm Card (WCHH UK ltd) for their help and support in delivering teaching.

1. NHS Scotland: Sterile Services Provision Review Group: $1^{\text {st }}$ Report (The Glennie Framework). Edinburgh: The Stationery Office, 2001.

2. The report of an independent review of endoscope decontamination in Northern Ireland. Department of Health, Social Services and Public Safety, Belfast 2005. http: //www.dhsspsni.gov.uk/endoscopereport.pdf.
3. Bagg J, Smith A J, Hurrell D, McHugh S, Irvine G Pre-sterilization cleaning of re-usable instruments in general dental practice. Br Dent J 2007; 202: E22.

4. Bagg J, Smith A J, Hurrell D, McHugh S. Sterilisation of re-usable instruments in general dental practice. Br Dent J 2007; 203: E16.

5. Smith A, Creanor S, Hurrell D, Bagg J, McCowan M. Management of infection control in dental practice. J Hosp Infect 2009; 71: 353-358.

6. The first five years, 3rd ed (interim 2008). A framework for undergraduate dental education. London: General Dental Council, 2008.

7. NHS Scotland: Sterile Services Provision Review Group. Survey of decontamination in general dental practice. Edinburgh: The Stationery Office, 2004. www.scotland.gov.uk/ Publications/2004/11/20093/45220

8. Health Protection Scotland. Local decontamination units: guidance on the requirements for equipment facilities and management. 2007. www.documents. hps.scot.nhs.uk/hai/decontamination/publications/ Idu-001-02-v1-2.pdf.

9. Lockhart D E A, Smith A J. An evaluation of a pilot study of a web-based educational initiative for educating and training undergraduate dental students in infection prevention. Br Dent J 2009: 207: 223-226.

10. NHS Estates (England). Health Technical Memorandum 2010: Sterilizers. HMSO, London: The Stationery Office.

11. NHS Estates (Scotland). Scottish Health Technical Memorandum 2010: Sterilizers. Edinburgh: The Stationery Office.

12. NHS Estates (England). Health Technical Memorandum 2030: Washer disinfectors. HMSO, The Stationery Office, 1997.

13. NHS Estates (Scotland). Scottish Health Technical Memorandum 2030: Washer disinfectors. HMSO, Edinburgh: The Stationery Office, 2001.

14. Medical Devices Agency. Benchtop steam sterilizers - Guidance on purchase, operation and maintenance. Device Bulletin 2002(06) October 2002.

15. Institute of Decontamination Sciences. www.idsc-uk.co.uk/.

16. Eastwood Park. www.eastwoodpark.co.uk/ t_courses_decon1.htm.

17. National Vocational Qualifications www.nhscareers nhs.uk/details/Default.aspx?ld=829.

18. NES e-learning programme www.decontamination. scot.nhs.uk/Ims/nhs_splash/nhs_splash.asp. 